\title{
Solvent-Mediated Activation/Deactivation of Photoinduced Elec- tron-Transfer in a Molecular Dyad
}

\author{
Christopher B. Larsen, ${ }^{\dagger} *$ George A. Farrow ${ }^{\ddagger}$ Liam D. Smith,${ }^{\ddagger}$ Martin V. Appleby, ${ }^{\ddagger}$ Dimitri Cheku- \\ laev ${ }^{\ddagger}$ Julia A. Weinstein, ${ }^{* *}$ and Oliver S. Wenger ${ }^{\dagger *}$ \\ †Department of Chemistry, University of Basel, St. Johanns-Ring 19, Basel CH-4056, Switzerland. \\ "Department of Chemistry, University of Sheffield, Sheffield S3 7HF, United Kingdom. \\ ${ }^{\S}$ Current Address: Stanford PULSE Institute, SLAC National Accelerator Laboratory, Menlo Park, CA 94025, USA. \\ KEYWORDS: Electron-Transfer, Donor-Acceptor Systems, Time-Resolved Electronic and Vibrational Spectroscopy, Molec- \\ ular Electronics, Photochemistry
}

\begin{abstract}
Herein is presented a molecular dyad comprised of a $\left[\mathrm{Ru}(\mathrm{bpy})_{3}\right]^{2+}$ photosensitizer and an anthraquinone (AQ) acceptor coupled by an ethynyl linker ([Ru(bpy $\left.)_{2}(\text { bpy-cc-AQ) }]^{2+}\right)$, in which activation/deactivation of photoinduced electron-transfer from the $\left[\mathrm{Ru}(\mathrm{bpy})_{3}\right]^{2+}$ photosensitizer to the AQ acceptor is achieved and characterized as a function of the dielectric constant and hydrogenbond donating ability of the solvent used. It is demonstrated that the rate of photoinduced electron-transfer can be modulated over several orders of magnitude $\left(10^{5}-10^{11} \mathrm{~s}^{-1}\right)$ by choice of solvent. Nanosecond transient absorption spectra are dominated by MLCT signals and exhibit identical decay kinetics to the corresponding emission signals. Ultrafast transient absorption and time-resolved infrared spectroscopies provide direct evidence for the formation of the charge-separated (CS) state and rapid (on the order of a few picoseconds) establishment of an excited-state pseudo-equilibrium.
\end{abstract}

\section{INTRODUCTION}

Stimulus-mediated activation/deactivation of photoinduced electron-transfer (PET) is of significant interest with respect to molecular switches and molecular logic operations. ${ }^{1-6}$ To date, much research in this area has focused on two key approaches: (1) modulation of electronic coupling between a donor and acceptor through photoisomerization of a photochromic bridge $;^{7-}$

11 (2) modulation of driving force for electron-transfer (ET) through binding of chemical stimuli to a redox-active unit. ${ }^{1-4,6}$, 12-14 The latter approach has also proved useful for molecular sensing, whereby photoluminescence quenching via intramolecular ET is modulated through changes in driving force for ET upon analyte binding. ${ }^{13-18}$

Whilst systems employing the aforementioned stimuli are now well-developed, the use of solvent as a stimulus to modulate ET rates and thereby activate/deactivate PET seems less explored. This is somewhat surprising, given that the solvent-dependence of ET kinetics is well-established. ${ }^{19-20}$ The most well-known example of solvent-mediated activation of photoluminescence quenching via intramolecular ET is arguably the molecular light-switch effect of $\left[\mathrm{Ru}(\mathrm{bpy})_{2}(\mathrm{dppz})\right]^{2+}\left(\mathrm{bpy}=2,2^{\prime}\right.$-bipyridine, dppz $=$ dipyrido $\left[3,2-a: 2^{\prime}, 3^{\prime}-c\right]$ phenazine $)$, wherein the complex exhibits ${ }^{3}$ MLCT luminescence in aprotic solvent or in the presence of DNA, which is quenched in protic solvent (Figure 1, left). ${ }^{21}$ The underlying mechanism for the phenomenon is dependent on the dual nature of the dppz ligand, wherein the phenazine-like and bipyridine-like sections possess localized acceptor orbitals, ${ }^{22}$ competition between entropic and energetic factors which favor a $\left[\mathrm{Ru}(\mathrm{bpy})_{3}\right]^{2+}$-localized photoluminescent ${ }^{3}$ MLCT state or a non-emissive charge-separated (CS) state (wherein the excited electron is localized on the phenazine-sec- tion of the dppz ligand), respectively, is influenced by both solvent dielectric and hydrogen-bonding. ${ }^{23-24}$ Importantly, there is no state inversion: the CS state is lower in energy in all solvents.
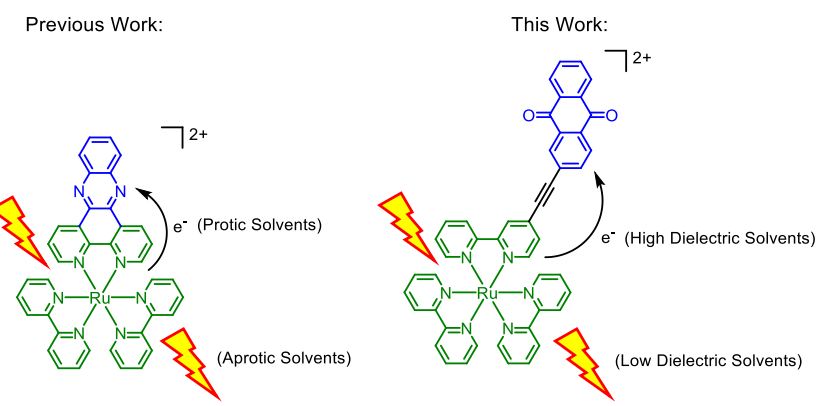

Figure 1. Left: Solvent-mediated activation of PET in the 'molecular light-switch', [Ru(bpy) $\left.)_{2}(\mathrm{dppz})\right]^{2+} \cdot{ }^{23-24}$ Right: Solvent-mediated activation of PET in $\left[\mathrm{Ru}(\mathrm{bpy})_{2} \text { (bpy-cc-AQ) }\right]^{2+}$ investigated here.

Previous work from our group on $\left[\mathrm{Ru}(\mathrm{bpy})_{3}\right]^{2+}$-photosensitizerAQ acceptor dyads bridged with weakly coupling $p$-xylene and $p$-dimethoxybenzene linkers demonstrated that ET can be deactivated in dichloromethane $\left(\mathrm{CH}_{2} \mathrm{Cl}_{2}\right)$ and activated in acetonitrile $(\mathrm{MeCN})$, reducing the lifetime of the luminescent excited state of the $\left[\mathrm{Ru}(\mathrm{bpy})_{3}\right]^{2+}$-core by up to one order of magnitude. ${ }^{25}$ This effect primarily arises from the close match of the AQ reduction potential with the ${ }^{3}$ MLCT excited-state oxidation potential of $\left[\mathrm{Ru}(\mathrm{bpy})_{3}\right]^{2+}$, which, combined with the solvent-dependence of the latter, allows for tuning of the driving force of ET from endergonic to exergonic. We hypothesized that replacement of the weakly coupling $p$-xylene and $p$-dimethoxybenzene linkers with a strongly coupling ethynyl linker could result in significantly enhanced solvent-mediated activation/deactivation of ET. 
Herein is presented a molecular dyad comprised of a $\left[\mathrm{Ru}(\mathrm{bpy})_{3}\right]^{2+}$ photosensitizer and an anthraquinone (AQ) acceptor coupled by an ethynyl linker ([Ru(bpy $)_{2}($ bpy-cc-AQ $\left.\left.)\right]^{2+}\right)$, whereby quenching of ${ }^{3} \mathrm{MLCT}$ photoluminescence via intramolecular ET is modulated as a function of solvent dielectric constant and hydrogen-bonding over several orders of magnitude.

This behavior has been characterized using a combination of steady-state electronic absorption and emission spectroscopies, electrochemical and spectroelectrochemical analyses, nanosecond transient absorption and emission spectroscopies, time-correlated single photon counting measurements, femtosecond transient absorption spectroscopy in the UV-Vis-NIR spectral regions and femtosecond time-resolved infrared spectroscopy. ${ }^{26}$

\section{EXPERIMENTAL}

General experimental, synthesis and characterization data, and instrument details are presented in the supporting information (Pages S2-S10).

\section{RESULTS AND DISCUSSION}

\section{Synthesis and Characterization}

The bpy-cc-AQ ligand was prepared in one step from 2-bromo9,10-anthraquinone and 4-ethynyl-2,2'-bipyridine through a Sonogashira-Hagihara palladium-catalyzed cross-coupling in $76 \%$ yield. The ligand was then complexed using the precursor $\left[\mathrm{RuCl}_{2}(\mathrm{bpy})_{2}\right]$, to afford [Ru(bpy $)_{2}$ (bpy-cc-AQ) $]\left(\mathrm{PF}_{6}\right)_{2}$ in $89 \%$ yield. A portion of $\left[\mathrm{Ru}(\mathrm{bpy})_{2}(\mathrm{bpy}-\mathrm{cc}-\mathrm{AQ})\right]\left(\mathrm{PF}_{6}\right)_{2}$ was further eluted through an Amberlite® IRA-400 chloride ion-exchange column to afford $\left[\mathrm{Ru}(\mathrm{bpy})_{2}\right.$ (bpy-cc-AQ) $] \mathrm{Cl}_{2}$ in quantitative yield. Characterization data is presented in the SI (pages S6S10).

\section{Electrochemistry}

Two key design concepts of $\left[\mathrm{Ru}(\mathrm{bpy})_{2}(\mathrm{bpy}-\mathrm{cc}-\mathrm{AQ})\right]^{2+}$ are the matching of the $\mathrm{E}_{1 / 2}\left(\mathrm{AQ}^{0 / \bullet-}\right)$ and $\mathrm{E}_{1 / 2}\left(\mathrm{Ru}^{\mathrm{III}} / * \mathrm{Ru}^{\mathrm{II}}\right)$ potentials, and the pronounced solvent-dependence of $\mathrm{E}_{1 / 2}\left(\mathrm{AQ}^{0 / \bullet-}\right)$. Cyclic voltammograms of $\left[\mathrm{Ru}(\mathrm{bpy})_{2}(\mathrm{bpy}-\mathrm{cc}-\mathrm{AQ})\right]\left(\mathrm{PF}_{6}\right)_{2}$ recorded in a range of solvents with varying dielectric constants are presented in Figure 2a, with isolated oxidation and reduction processes presented in Figures S11-S12. In all solvents, one reversible reduction process assigned to $\mathrm{AQ}^{0 / \bullet}$ and one oxidation process assigned to the $\mathrm{Ru}^{\mathrm{III} / \mathrm{II}}$ couple can be observed. Scanning to more negative potentials yields a set of convoluted quasi-reversible reduction processes at potentials expected for $\mathrm{AQ}^{-/ 2-}$ and the three bpy ${ }^{0 / \bullet-}$ processes. ${ }^{27}$ The only solvent in which these less important processes could be clearly distinguished was $N, N$-dimethylformamide (DMF, Figure S13).

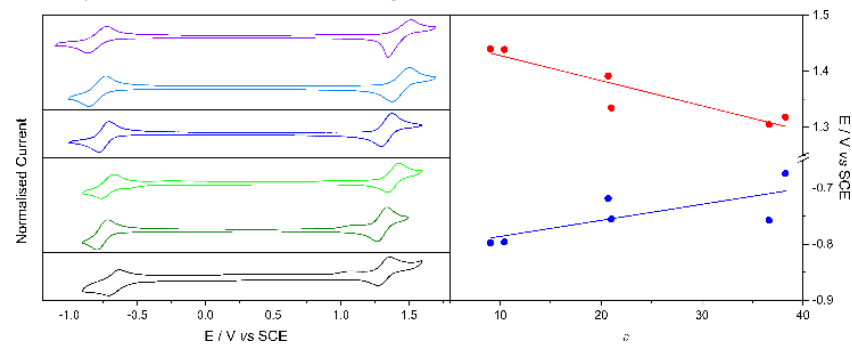

Figure 2. Left: Cyclic voltammograms of $\left[\mathrm{Ru}(\mathrm{bpy})_{2}\right.$ (bpy-cc$\mathrm{AQ})]\left(\mathrm{PF}_{6}\right)_{2}$ recorded as $1 \mathrm{mM}$ solution in $\mathrm{CH}_{2} \mathrm{Cl}_{2}$ (purple), 1,2-dichloroethane (light blue), butyronitrile (dark blue), acetone (light green), MeCN (dark green) and DMF (black) with $0.1 \mathrm{M}$ $\left[\mathrm{Bu}_{4} \mathrm{~N}\right] \mathrm{PF}_{6}$ electrolyte at scan-rate of $200 \mathrm{mV} \mathrm{s}^{-1}$. Typical currents were of the order of 10-40 $\mu \mathrm{A}$. Right: Trends in $\mathrm{E}_{1 / 2}\left(\mathrm{AQ} / \mathrm{AQ}^{*}\right.$ ) (blue) and $\mathrm{E}_{1 / 2}\left(\mathrm{Ru}^{\mathrm{III}} / \mathrm{Ru}^{\mathrm{II}}\right)$ (red) as a function of solvent dielectric constant.
In Figure 2b, two clear trends with increasing solvent dielectric constant $(\varepsilon)$ can be observed: an anodic shift of $\mathrm{E}_{1 / 2}\left(\mathrm{AQ} / \mathrm{AQ}^{*}\right)$ and a cathodic shift of $\mathrm{E}_{1 / 2}\left(\left[\mathrm{Ru}(\mathrm{bpy})_{3}\right]^{3+} /\left[\mathrm{Ru}(\mathrm{bpy})_{3}\right]^{2+}\right)$. Both trends are linear with respect to $\varepsilon$, yielding a linear dependence of $\Delta \mathrm{E}_{1 / 2}$ on $\varepsilon$ (Table $\mathrm{S} 1$ ). $\Delta \mathrm{E}_{1 / 2}$ is commonly used to estimate the energy of a CS state, ${ }^{25,27-30}$ but assumes no electronic interaction between the separated charges; in $\left[\mathrm{Ru}(\mathrm{bpy})_{2}(\mathrm{bpy}-\mathrm{cc}-\mathrm{AQ})\right]^{2+}$, the ethynyl linker imbues strong electronic coupling, likely resulting in overestimation of the CS state energy. ${ }^{31-32}$ However, trends in $\Delta \mathrm{E}_{1 / 2}$ act as a useful proxy for trends in the CS state energy, also in the case of $\left[\mathrm{Ru}(\mathrm{bpy})_{2}(\mathrm{bpy}-\mathrm{cc}-\mathrm{AQ})\right]^{2+}$.

Driving force parameters for oxidative quenching of the ${ }^{3}$ MLCT state via ET $\left(\Delta G_{E T}\right)$ and charge-recombination $\left(\Delta G_{C R}\right)$ estimated from the electrochemical data using the Weller equation (Eq. 1) are presented in Table $1 .^{33}$

$$
\begin{aligned}
& \Delta G_{E T}=e \cdot\left(E_{R u^{I I I / I I}}^{0}-E^{0}{ }_{A Q^{0 /-}}\right)-E_{00}-\frac{e^{2}}{4 \pi \cdot \varepsilon_{0} \cdot \varepsilon \cdot r_{D A}} \\
& \Delta G_{C R}=-\Delta G_{E T}-E_{00}
\end{aligned}
$$

In Eq. 1a, e is the elementary charge $\left(1.602 \times 10^{-19} \mathrm{C}\right), \mathrm{E}_{00}$ the $\left[\mathrm{Ru}(\mathrm{bpy})_{3}\right]^{2+}$-like ${ }^{3} \mathrm{MLCT}$ energy, estimated from the emission spectrum of $\left[\mathrm{Ru}(\mathrm{bpy})_{2}(\mathrm{bpy}-\mathrm{cc}-\mathrm{AQ})\right]\left(\mathrm{PF}_{6}\right)_{2}$ in a frozen 2-methyltetrahydrofuran glass at $1.97 \mathrm{eV}$ (vide infra), $\varepsilon_{0}$ the vacuum permittivity $\left(8.854 \times 10^{-12} \mathrm{~F} \mathrm{~m}^{-1}\right), \varepsilon$ the solvent dielectric constant, and $\mathrm{r}_{\mathrm{DA}}$ the donor-acceptor distance, defined herein as the distance between the Ru core and the central point of the AQ acceptor (12.8 $\AA$ from energy-minimized molecular mechanics model). $\Delta G_{E T}$ is estimated to be positive in all solvents, ranging from $0.15 \mathrm{eV}$ in $\mathrm{CH}_{2} \mathrm{Cl}_{2}$ to $0.06 \mathrm{eV}$ in $\mathrm{MeCN}$. Whilst the Weller equation includes a solvent electrostatic work term, it was developed for bimolecular systems and therefore does not account for electronic interaction between close intramolecular charges. These values are therefore likely to be overestimated, and the actual driving forces for ET may be negative in the solvents with higher dielectric constants. The linear trend in $\Delta G_{E T}$ with respect to $\varepsilon$ therefore seems more important. The semi-classical Marcus-Hush model for ET states (Eq. 2): ${ }^{34}$

$$
k_{E T}=\sqrt{\frac{\pi}{\hbar^{2} \lambda k_{B} T}} H_{D A}{ }^{2} e^{\left(\frac{-\left(\lambda+\Delta G_{E T}\right)^{2}}{4 \lambda k_{B} T}\right)}
$$

Table 1. Summary of dielectric constants and PET parameters derived from cyclic voltammetry.

\begin{tabular}{|c|c|c|c|}
\hline Solvent & $\varepsilon^{35}$ & $\Delta \mathrm{G}_{\mathrm{ET}^{\mathrm{a}}} / \mathrm{eV}$ & $\Delta \mathrm{G}_{\mathrm{CR}}^{\mathrm{b}} / \mathrm{eV}$ \\
\hline Dichloromethane & 9.08 & 0.15 & -2.12 \\
\hline 1,2-Dichloroethane & 10.4 & 0.16 & -2.13 \\
\hline Butyronitrile & 20.7 & 0.09 & -2.06 \\
\hline Acetone & 21.0 & 0.07 & -2.04 \\
\hline Acetonitrile & 36.6 & 0.06 & -2.03 \\
\hline
\end{tabular}

${ }^{\mathrm{a}}$ Driving force for forward ET to the AQ acceptor. ${ }^{\mathrm{b}}$ Driving force for charge-recombination.

In Eq. $2, k_{E T}$ is the ET rate constant, $\lambda$ the reorganization energy, $k_{B}$ the Boltzmann constant, $H_{D A}$ the electronic coupling between donor and acceptor, and $\Delta G_{E T}$ the reaction free energy for ET. The implication herein is that, given the linear increase in $\Delta G_{E T}$ with $\varepsilon$ and exponential dependence of $k_{E T}$ on $\Delta G_{E T}$, an exponential dependence of $k_{E T}$ with respect to $\varepsilon$ is to be expected.

\section{Optical Spectroscopy}

The electronic absorption and emission spectra of $\left[\mathrm{Ru}(\mathrm{bpy})_{2}(\mathrm{bpy}-\mathrm{cc}-\mathrm{AQ})\right]\left(\mathrm{PF}_{6}\right)_{2}$ in $\mathrm{CH}_{2} \mathrm{Cl}_{2}$ are presented in Figure 
3. The absorption spectrum exhibits key features at $288(\varepsilon=$ $\left.82.6 \times 10^{3} \mathrm{M}^{-1} \mathrm{~cm}^{-1}\right)$ and $470 \mathrm{~nm}\left(19.4 \times 10^{3} \mathrm{M}^{-1} \mathrm{~cm}^{-1}\right)$. The former feature, assigned to bpy-based $\pi, \pi^{*}$ transitions, is identical to that of $\left[\mathrm{Ru}(\mathrm{bpy})_{3}\right]^{2+}$, but exhibits an additional low energy shoulder most likely associated with AQ-based $\pi, \pi^{*}$ transitions. The 470-nm feature, assigned to MLCT transitions, bears almost identical band structure to that of $\left[\mathrm{Ru}(\mathrm{bpy})_{3}\right]^{2+}$, but exhibiting a bathochromic shift relative to that of $\left[\mathrm{Ru}(\mathrm{bpy})_{3}\right]^{2+}$ $(453 \mathrm{~nm} \text { in } \mathrm{MeCN})^{36}$ due to the extended conjugation associated with the ethynyl linker. The electronic absorption spectrum of $\left[\mathrm{Ru}(\mathrm{bpy})_{2}(\mathrm{bpy}-\mathrm{cc}-\mathrm{AQ})\right]\left(\mathrm{PF}_{6}\right)_{2}$ is reasonably insensitive to solvent, exhibiting only subtle differences (Figure S14).

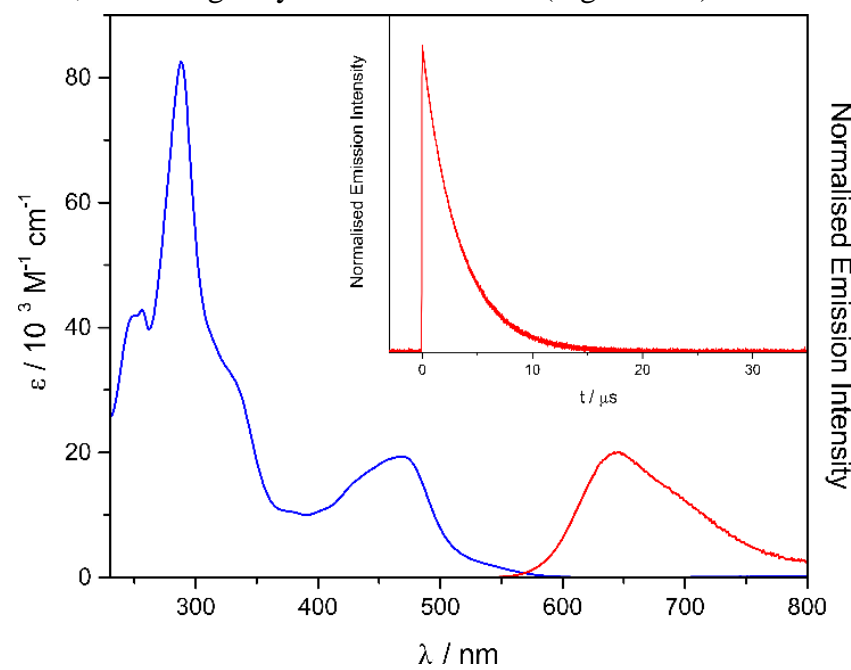

Figure 3. Electronic absorption (blue) and emission (red, $\lambda_{\mathrm{ex}}=475$ $\mathrm{nm})$ spectra of $\left[\mathrm{Ru}(\mathrm{bpy})_{2}\right.$ (bpy-cc-AQ) $]\left(\mathrm{PF}_{6}\right)_{2}$ recorded as a $20 \mu \mathrm{M}$ solution in $\mathrm{CH}_{2} \mathrm{Cl}_{2}$. Inset: Decay of the emission signal $\left(\lambda_{\mathrm{ex}}=532\right.$ $\mathrm{nm}$, detection at $635 \mathrm{~nm}$ ).

Upon selective photoexcitation into the MLCT absorption manifold with wavelengths longer than $400 \mathrm{~nm},{ }^{3} \mathrm{MLCT}$ photoluminescence with emission maxima ranging from 642-664 $\mathrm{nm}$ can be observed (

Table 2). As with $\lambda_{\text {abs }}, \lambda_{\text {em }}$ exhibits a bathochromic shift with respect to that of $\left[\mathrm{Ru}(\mathrm{bpy})_{3}\right]^{2+}(618 \mathrm{~nm}$ in $\mathrm{MeCN})$. Full-width half-maxima (FWHM) values range from 2380-2970 $\mathrm{cm}^{-1}$ $\left(\triangle \mathrm{FWHM}=590 \mathrm{~cm}^{-1}\right)$, with Stokes shifts $\left(\tilde{v}_{\mathrm{st}}\right)$ ranging from $5700-6260 \mathrm{~cm}^{-1}\left(\Delta \tilde{v}_{\mathrm{st}}=560 \mathrm{~cm}^{-1}\right)$, consistent with that observed for $\left[\mathrm{Ru}(\mathrm{bpy})_{3}\right]^{2+37}$ indicating that the nature of the photoluminescence is indeed $\left[\mathrm{Ru}(\mathrm{bpy})_{3}\right]^{2+}$-like ${ }^{3} \mathrm{MLCT}$. The energy of the ${ }^{3}$ MLCT state, estimated from the emission spectrum of $\left[\mathrm{Ru}(\mathrm{bpy})_{2}(\mathrm{bpy}-\mathrm{cc}-\mathrm{AQ})\right]\left(\mathrm{PF}_{6}\right)_{2}$ in a frozen 2-methyltetrahydrofuran glass at $77 \mathrm{~K}$ (Figure $\mathrm{S} 15$ ), is decreased from $2.12 \mathrm{eV}$ for $\left[\mathrm{Ru}(\mathrm{bpy})_{3}\right]^{2+}$ to $1.97 \mathrm{eV}$.

A positive consequence of the extended ligand conjugation is a significantly enhanced photoluminescence quantum yield $(\phi)$ and increased photoluminescence lifetime $(\tau)$ in low polarity solvents compared to $\left[\mathrm{Ru}(\mathrm{bpy})_{3}\right]^{2+}$. This phenomenon was also observed for an analogous dyad incorporating a dimethoxybenzene linker, ${ }^{25}$ and Castellano and coworkers have also reported similar behavior in $\left[\mathrm{Cu}(\text { phen })_{2}\right]^{+}$complexes (phen $=1,10$-phenanthroline) upon extension of the ligand $\pi$-conjugation. ${ }^{38}$

Given the consistent nature of the emissive state across the investigated solvent range, the influence of solvent dielectric on photoluminescence quantum yields $(\phi)$ and lifetimes $(\tau)$ is of particular interest. For $\left[\mathrm{Ru}(\mathrm{bpy})_{3}\right]^{2+}$, both radiative and non-radiative rate constants are essentially solvent-independent, ${ }^{37}$ resulting in only a relatively minor increase in $\phi$ and $\tau$ with the increase in solvent polarity. For $\left[\mathrm{Ru}(\mathrm{bpy})_{2}(\mathrm{bpy}-\mathrm{cc}-\mathrm{AQ})\right]\left(\mathrm{PF}_{6}\right)_{2}$, a much more dramatic effect is observed. In aprotic solvents, both $\phi$ and $\tau$ decrease by three orders of magnitude with solvent polarity increasing from $\mathrm{CH}_{2} \mathrm{Cl}_{2}$ to $\mathrm{MeCN}$. $k_{r}$ remains relatively constant $\left(3.5-8.9 \times 10^{4} \mathrm{~s}^{-1}\right.$;

Table 2$)$ - consistent with the behavior of $\left[\mathrm{Ru}(\mathrm{bpy})_{3}\right]^{2+}$; instead, the drastic change in $\phi$ and $\tau$ is a consequence of the change in $\Sigma k_{n r}$ with solvent dielectric constant $(\varepsilon)$, which exhibits an exponential dependence on $\varepsilon$ (Figure S18). As $\Sigma k_{n r}$ represents the sum of all non-radiative decay processes from the emissive ${ }^{3}$ MLCT state (Eq. 3), which includes non-radiative decay to the ground-state $\left(k_{n r(M L C T)}\right)$ and ET to the AQ acceptor $\left(k_{E T}\right)$, the large deviation from the behavior of $\left[\mathrm{Ru}(\mathrm{bpy})_{3}\right]^{2+}$ can be assigned to solvent-mediated activation of ET.

Table 2. Summary of spectroscopic and kinetic properties for $\left[\operatorname{Ru}(\mathrm{bpy})_{2}(\mathrm{bpy}-\mathrm{cc}-\mathrm{AQ})\right]^{2+}$.

\begin{tabular}{|c|c|c|c|c|c|c|c|c|c|c|}
\hline Solvent & $\varepsilon$ & $\begin{array}{c}\lambda_{\text {abs }} / \\
\mathrm{nm}\end{array}$ & $\begin{array}{c}\lambda_{\mathrm{em}} / \\
\mathrm{nm}\end{array}$ & $\begin{array}{c}\text { FWHM / } \\
\mathrm{cm}^{-1}\end{array}$ & $\tilde{v}_{\mathrm{st}} / \mathrm{cm}^{-1}$ & $\phi$ & $\tau / \mathrm{ns}$ & $\begin{array}{c}k_{\text {obs }} / \\
10^{6} \mathrm{~s}^{-1 \mathrm{e}}\end{array}$ & $\begin{array}{c}k_{\mathrm{r}} / \\
10^{4} \mathrm{~s}^{-1 \mathrm{f}}\end{array}$ & $\begin{array}{c}\Sigma k_{\mathrm{nr}} / \\
10^{6} \mathrm{~s}^{-1 \mathrm{~g}}\end{array}$ \\
\hline Dichloromethane $^{\mathrm{a}}$ & 9.08 & 469 & 647 & 2410 & 5870 & 0.226 & 3350 & 0.30 & 6.8 & 0.23 \\
\hline $\begin{array}{l}\text { 1,2-Dichloro- } \\
\text { ethane }^{\mathrm{a}}\end{array}$ & 10.4 & 470 & 642 & 2380 & 5700 & 0.235 & 3660 & 0.27 & 6.4 & 0.21 \\
\hline Butyronitrile $^{\mathrm{a}}$ & 20.7 & 470 & 664 & 2490 & 6260 & 0.016 & 330 & 5.0 & 3.5 & 5.0 \\
\hline Acetone $^{\mathrm{a}}$ & 21.0 & 469 & 664 & 2480 & 6220 & 0.007 & 200 & 3.0 & 4.9 & 3.0 \\
\hline Acetonitrile $^{\mathrm{a}}$ & 36.6 & 470 & 662 & 2570 & 6170 & 0.0006 & 6.7 & 149 & 8.9 & 149 \\
\hline 2-Propanol ${ }^{\mathrm{b}}$ & 18.3 & 466 & 648 & 2460 & 6030 & $-\mathrm{c}$ & 513 & 2.0 & - & - \\
\hline Ethanol $^{\mathrm{b}}$ & 24.6 & 466 & 648 & 2720 & 6030 & $-c$ & 8.1 & 120 & - & - \\
\hline Methanol $^{\mathrm{b}}$ & 32.6 & 466 & 649 & 2970 & 6050 & $-c$ & 0.58 & 1700 & - & - \\
\hline Water $^{\mathrm{b}}$ & 78.5 & 472 & 648 & 2890 & 5750 & $-c$ & $\begin{array}{c}< \\
0.10^{\mathrm{d}}\end{array}$ & $>10000$ & - & - \\
\hline
\end{tabular}

${ }^{a}$ Recorded using $\mathrm{PF}_{6}$ salt. ${ }^{\mathrm{b}}$ Recorded using $\mathrm{Cl}$ salt. ${ }^{\mathrm{c}}$ Not determined due to values in water and methanol lying below detection limit. ${ }^{\mathrm{d}}$ Could not be deconvoluted from the instrument response. ${ }^{\mathrm{e}} k_{o b s}=1 / \tau .{ }^{\mathrm{f}} k_{r}=\phi / \tau .{ }^{\mathrm{g}} \sum k_{n r}=k_{o b s}-k_{r}$. 
This behavior is mimicked by $k_{o b s}\left(=\tau^{-1}\right)$, which closely models $\Sigma k_{n r}$ due to the large difference between $k_{r}$ and $\Sigma k_{n r}$.

$\sum k_{n r}=k_{n r(M L C T)}+k_{E T}$

In protic solvents, $k_{o b s}$ also changes exponentially with $\varepsilon$, but is much more strongly dependent on $\varepsilon$ than in aprotic solvents (Figure 4 , left). $k_{o b s}$ exhibits an apparently exponential dependence on both the solvent Gutmann Acceptor Number (AN) and the Reichardt Parameter $\left(\mathrm{E}_{\mathrm{T}}^{\mathrm{N}}\right)$ in protic solvents (Figure 4, right), known measures for solvent Lewis acidity which proxy hydrogen-bond donor strength in the presence of a Lewis base such as AQ or AQ*-39-43

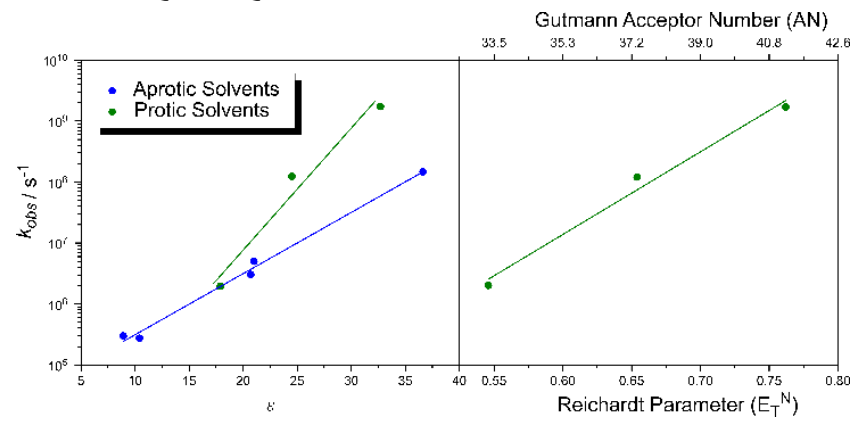

Figure 4. (Left) Dependence of $\mathrm{k}_{\mathrm{obs}}$ on solvent dielectric constant. (Right) Dependence of $\mathrm{k}_{\mathrm{obs}}$ on solvent Gutmann acceptor number and Reichardt parameter. ${ }^{40,42-43}$ Error bars are smaller than the data points. Trends are indicative only.

There is no obvious correlation between these hydrogen-bond donor strength proxies and the kinetic behavior in aprotic solvents (Figure S19), indicating that solvent dielectric constant is the more important parameter in aprotic solvents whereas hydrogen-bond donor strength is the more influential parameter in protic solvents. Whilst such a trend is not entirely unexpected, ${ }^{44}$ it highlights hydrogen-bonding as a secondary tool for solventmediated activation of ET, which affects the rates of ET significantly greater than $\varepsilon$ in aprotic solvents.

\section{Nanosecond Transient Absorption Spectroscopy}

To further understand the solvent-dependent interplay between the ${ }^{3}$ MLCT and CS states, transient absorption (TA) spectroscopy was performed. It was originally hypothesized that different solvents would elicit very different behavior in TA spectra: in less polar solvents the TA spectra were expected to exhibit features associated with the ${ }^{3}$ MLCT state, with lifetimes matching those obtained from the decay of the emission signal; in more polar and hydrogen-bonding solvents, it was expected that TA spectra would predominantly exhibit features associated with the CS state, and with lifetimes different to those observed for the emissive MLCT state.

In $\mathrm{CH}_{2} \mathrm{Cl}_{2}$, upon excitation at $532 \mathrm{~nm}$ with $10 \mathrm{~ns}$ laser pulses, a TA spectrum exhibiting a ground-state bleach (GSB) coinciding with the MLCT absorption feature at $470 \mathrm{~nm}$, and excitedstate absorption (ESA) features at 367, 590 and $780 \mathrm{~nm}$ was obtained (Figure 5). The recovery of the GSB and the decay of the ESA are monoexponential, with time constants matching that of the emission lifetime. These results are strongly indicative of the same $\left({ }^{3} \mathrm{MLCT}\right)$ excited state being detected in both emission and TA experiments. Differences between this spectrum and that of $\left[\mathrm{Ru}(\mathrm{bpy})_{3}\right]^{2+}$, notably those at wavelengths > $500 \mathrm{~nm}$, are therefore likely due to the extended conjugation imbued by the ethynyl linker. The central ESA feature around
$600 \mathrm{~nm}$ qualitatively resembles AQ*- (Figure S21) and could indicate that the MLCT excited state is significantly delocalized onto the AQ acceptor (i.e. has some $\mathrm{AQ}^{--}$character).

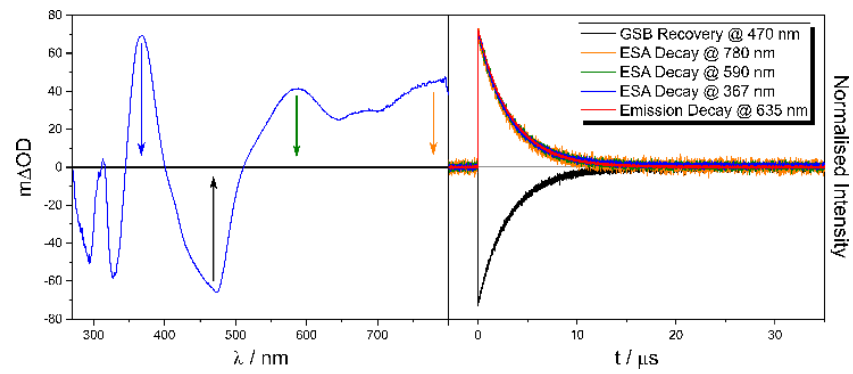

Figure 5. (Left) Transient absorption spectrum (not emission-corrected) of $\left[\mathrm{Ru}(\mathrm{bpy})_{2}\right.$ (bpy-cc-AQ) $\left(\mathrm{PF}_{6}\right)_{2}$ recorded in $\mathrm{CH}_{2} \mathrm{Cl}_{2}$ at 293 $\mathrm{K}$ immediately following excitation with $532 \mathrm{~nm}$, ca. $10 \mathrm{~ns}$ laser pulses, time-integrated over an interval of $200 \mathrm{~ns}$. Arrows denote the positions for which kinetic traces are presented. (Right) Normalized GSB recovery, ESA decay and emission decay traces corresponding to the arrows in the transient absorption spectrum (left).

ns-TA spectra recorded in all solvents exhibit monoexponential kinetics matching those of the corresponding emission decays (Figures S22-S25). This was also observed for the analogous dyads reported by Hankache and Wenger, ${ }^{25}$ as well as in an unrelated system reported by Hammarström, ${ }^{45}$ which attributed the phenomenon to charge-recombination from the CS state $\left(k_{C R}\right)$ being significantly greater than the rate of charge-separation such that CS state does not accumulate sufficiently to be observed under the experimental conditions. Ultrafast spectroscopic measurements (vide infra) imply a pseudo-equilibrium in which the majority of the excited-state population resides in the MLCT state. Assuming positive driving force for electrontransfer, as implied by electrochemical studies (vide supra), this could provide a viable alternative explanation for the observed behavior. Emission-corrected TA spectra exhibit a subtle solvent-dependence of the central ESA around $600 \mathrm{~nm}$ (Figure 6, orange and red spectra), which may be a consequence of solvent-dependent changes in such a pseudo-equilibrium. Variable temperature studies undertaken to explore this possibility yielded complicated, inconclusive results (Page S18-S19) and may be subject to future kinetic modelling studies.

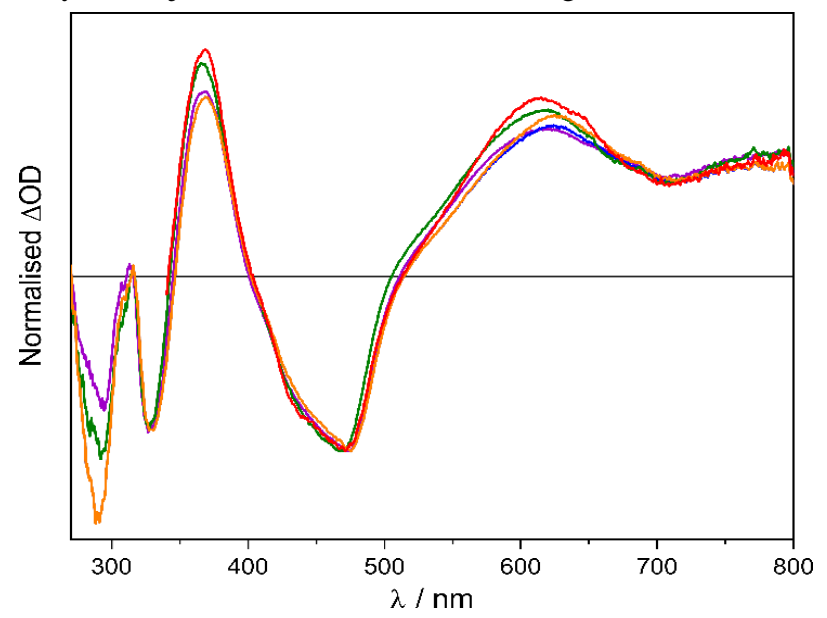

Figure 6. Emission-corrected transient absorption spectra of $\left[\mathrm{Ru}(\text { bpy })_{2}\right.$ (bpy-cc-AQ) $]\left(\mathrm{PF}_{6}\right)_{2}$ recorded in $\mathrm{CH}_{2} \mathrm{Cl}_{2}$ (purple), 1,2dichloroethane (blue), 2-propanol (green), butyronitrile (orange) and acetone (red) at $293 \mathrm{~K}$ immediately following excitation with $532 \mathrm{~nm}$, ca. $10 \mathrm{~ns}$ laser pulses, time-integrated over an interval of $200 \mathrm{~ns}$, normalized to the GSB at $470 \mathrm{~nm}$. 


\section{Ultrafast Transient Absorption Spectroscopy}

Ultrafast TA spectroscopy in both the UV-Vis $(370-750 \mathrm{~nm})$ and near-infrared (NIR, $950-1200 \mathrm{~nm}$ ) spectral regions was further employed to gain deeper understanding of the excitedstate dynamics at early timescales (Figure 7). $\mathrm{CH}_{2} \mathrm{Cl}_{2}$ and $\mathrm{MeCN}$ were chosen as the solvents for these measurements as they represent the two behavioral extremes within the range of aprotic solvents. The detailed analysis of the data by global fitting is presented in the SI (Figures S26-S32).

Upon $400 \mathrm{~nm}$ excitation with $\sim 80$ fs laser pulse in both solvents, the ground state bleach (GSB) centered at $475 \mathrm{~nm}$ associated with the MLCT transition, and the excited state absorption (ESA) features associated with the ${ }^{3}$ MLCT evolve within a few picoseconds, consistent with the behavior of the "core" moiety, $\left[\mathrm{Ru}(\mathrm{bpy})_{3}\right]^{2+}$. Analysis of the kinetics of bleach and transient features, in both solvents, reveal fast dynamics occurring on the picosecond timescale ( $\sim 11$ to 23 ps in $\mathrm{CH}_{2} \mathrm{Cl}_{2}, \sim 5$ to 66 ps in $\mathrm{MeCN})$. For both solvents, these early time dynamics result in a recovery of the bleach at $\sim 475 \mathrm{~nm}$, decay of the transient at $\sim 370 \mathrm{~nm}$ and growth of the transient $\sim 640 \mathrm{~nm}$.

These spectral / dynamic changes could be a result of vibrational relaxation and/or structural reorganization within the complex, as excess energy (originating from $400 \mathrm{~nm}$ excitation being at least $1 \mathrm{eV}$ higher in energy than the lowest, $<600 \mathrm{~nm}$, excited state) is redistributed. In $\mathrm{CH}_{2} \mathrm{Cl}_{2}$, the final state observed is "infinitely" long-lived, without any decay being observed on the 8-ns timescale of the experiment. In $\mathrm{MeCN}$, the final state decays with a lifetime of $\sim 4.9 \pm 1.1 \mathrm{~ns}$. In both cases, the long-lived features closely resemble those obtained from the
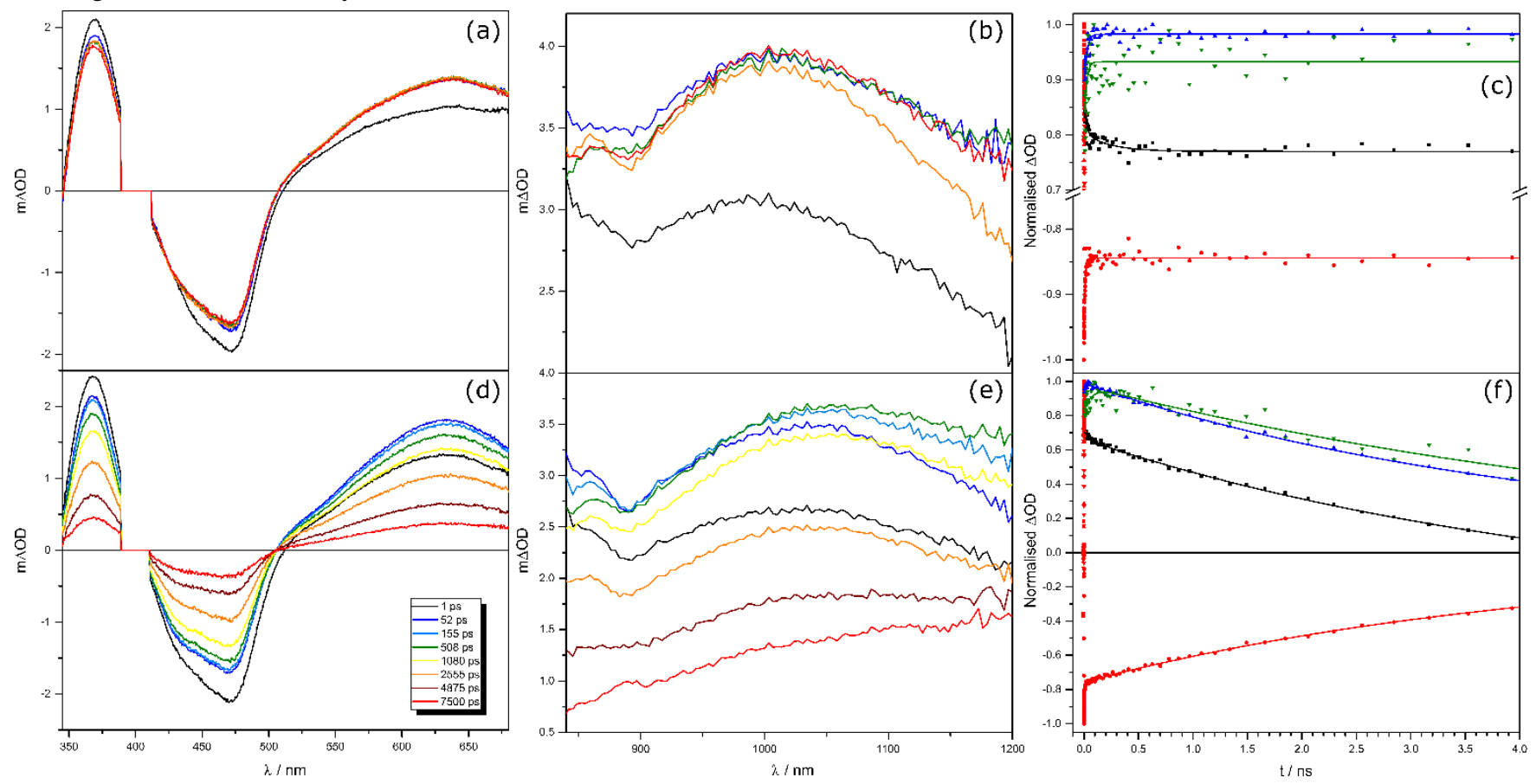

Figure 7. Transient absorption spectra of $\left[\mathrm{Ru}(\mathrm{bpy})_{2}\right.$ (bpy-cc-AQ) $]\left(\mathrm{PF}_{6}\right)_{2}$, in $\mathrm{CH}_{2} \mathrm{Cl}_{2}$ and $\mathrm{MeCN}$, in both visible $\left((\mathrm{a}) \mathrm{CH}_{2} \mathrm{Cl} 2,(\mathrm{~d}) \mathrm{MeCN}\right)$ and NIR ((b) $\mathrm{CH}_{2} \mathrm{Cl}_{2}$, (e) $\mathrm{MeCN}$ ) spectral regions, at specified delay times following excitation at $400 \mathrm{~nm}$ with laser pulses of ca. $80 \mathrm{fs}$ duration. Kinetic traces of integrated bands across both spectral regions ((c) $\mathrm{CH}_{2} \mathrm{Cl}_{2}$, (f) $\mathrm{MeCN}$ ). The kinetic parameters obtained are as follows. In $\mathrm{CH}_{2} \mathrm{Cl}_{2}$ (panel c): $350-390 \mathrm{~nm}$ range (ש); $23 \pm 15$ ps growth, decay $236 \pm 145 \mathrm{ps}$ and a constant; $420-490 \mathrm{~nm}(\bullet)$, decay $11 \pm 3$ ps and a constant; $550-675 \mathrm{~nm}(\boldsymbol{\Delta}), 23 \pm 4$ ps growth, and a constant; $930-1100 \mathrm{~nm}$ ( $\mathbf{\nabla}) 20 \pm 9$ ps growth, and a constant. In MeCN (panel f): $350-390 \mathrm{~nm}$ range (®); $66 \pm 19$ ps growth, $4.7 \pm 0.20 \mathrm{~ns}$ decay; $420-490 \mathrm{~nm}(\bullet), 9 \pm 2$ ps growth, $4.3 \pm 0.14 \mathrm{~ns}$ decay; $550-675 \mathrm{~nm}(\boldsymbol{\Delta})$, $5 \pm 3$ ps growth, $4.2 \pm 0.20 \mathrm{~ns}$ decay; $975-1150 \mathrm{~nm}(\boldsymbol{\nabla}) 66 \pm 28$ ps growth, $6.3 \pm 1.9 \mathrm{~ns}$ decay. nanosecond TA spectroscopy. Furthermore, the $\sim 4.9$ ns lifetime is consistent with the $3.8 \mathrm{~ns}$ lifetime obtained from time-correated single photon counting (TCSPC) measurements. Globa analysis of the excited state dynamics of ps component is consistent with the formation of the ${ }^{3} \mathrm{MLCT}$ state, supported by the observation of characteristic MLCT features in its evolution-associated difference spectrum (EAS; Figure S26). The 22.8 ps component exhibits identical features to the 1.25 ps component in both its EAS and decay-associated (DAS), and is therefore likely associated with features of the long-lived component (2. closely resemble the emission-corrected nanosecond TA spectra (Figure 6).

Global fit analysis of $\left[\mathrm{Ru}(\mathrm{bpy})_{2}(\mathrm{bpy}-\mathrm{cc}-\mathrm{AQ})\right]\left(\mathrm{PF}_{6}\right)_{2}$ in $\mathrm{MeCN}$ also identified three components, with the lifetimes of $5 \mathrm{ps}, 66$ ps and $5.1 \pm 1.2 \mathrm{~ns}$ (an average of 4.7, 4.2, and 6.3 ns obtained for 3 different spectral regions; we note that the timescale of the TA experiment is $8 \mathrm{~ns}$ and hence the error in determining the ns is relatively large) (Figure 7d,f). The spectral shape of identical to those obtained by the nanosecond TA in the same solvent. The value of $5.1 \mathrm{~ns}$ lifetime is consistent within the experimental uncertainty with the $3.8 \mathrm{~ns}$ lifetime obtained from the emission lifetime (TCSPC) measurements. ponents with lifetimes of $1.25 \mathrm{ps}, 22.8 \mathrm{ps}$ and $2.8 \mu \mathrm{s}$. The 1.25 
Importantly, there are spectral differences of the longest-lived species in $\mathrm{MeCN}$ and $\mathrm{CH}_{2} \mathrm{Cl}_{2}$ that may be attributed to an excited-state pseudo-equilibrium. The free AQ radical anion is typically characterized by an intense absorption at ca. $530 \mathrm{~nm} .{ }^{46}$ However, the electronic absorption spectrum of $\left[\mathrm{Ru}(\mathrm{bpy})_{2}(\mathrm{bpy}-\mathrm{cc}-\mathrm{AQ})\right]\left(\mathrm{PF}_{6}\right)_{2}$ electrochemically reduced at the first reduction potential of $-0.9 \mathrm{~V}$ vs SCE (Figure S21) has this absorption feature broadened and shifted to ca. $600 \mathrm{~nm}$ - likely a consequence of extended delocalization of the radical anion across the ligand imbued by the ethynyl linker. Subtracting the $\mathrm{CH}_{2} \mathrm{Cl}_{2}$ DAS spectrum from that in MeCN identifies an additional band at $620 \mathrm{~nm}$ that may be attributed to AQ*- (Figure S27), with the small spectral shift a consequence of the different oxidation state of $\mathrm{Ru}$ in the spectroelectrochemical and transient absorption measurements ( $\mathrm{Ru}^{\mathrm{II}}$ and $\mathrm{Ru}^{\mathrm{III}}$, respectively). The lower intensity of this feature with respect to the MLCT absorption features is likely due to the pseudo-equilibrium position favoring population of the MLCT state.

\section{Time-Resolved Infrared Spectroscopy}

The presence of distinct infrared absorption bands on the AQ acceptor and the -CC-linker was explored to further evaluate excited-state equilibration between the MLCT and CS states, using ultrafast time-resolved infrared (TRIR) spectroscopy in the range from 1100-2300 $\mathrm{cm}^{-1}$ (Figure 8 and S34). Studies were undertaken in $\mathrm{CH}_{2} \mathrm{Cl}_{2}$ and deuterated $\mathrm{MeCN}\left(\mathrm{d}_{3}-\mathrm{MeCN}\right)$ to allow access to a larger spectral window.

In the range from $1250-2300 \mathrm{~cm}^{-1}$, FTIR spectra of $\left[\mathrm{Ru}(\mathrm{bpy})_{2} \text { (bpy-cc-AQ) }\right]^{2+}$ display bands at 2115 (very weak, $v(\mathrm{C} \equiv \mathrm{C})), 1679(v(\mathrm{C}=\mathrm{O})$ of $\mathrm{AQ})$, and multiple bands characteristic of a coordinated bpy-ligand, at 1274, 1296, 1317, 1326, $1337,1420,1439,1447,1466,1595,1604$ and $1611 \mathrm{~cm}^{-1} \cdot{ }^{47-49}$ Upon excitation with $400 \mathrm{~nm}$, ca. 40 fs laser pulses, bleaching of the ground state absorption bands are observed, with instant formation of multiple transient IR-absorption bands, all of which appear shifted to lower energies in comparison to the ground state spectra, and occur at 1254, 1286, 1312, 1334, 1367, 1420, 1462, 1490, 1530, 1550, 1572 and $1655 \mathrm{~cm}^{-1}$. In both solvents, the $1679 \mathrm{~cm}^{-1}$ AQ C=O mode shifts to lower energy $\left(1650-1655 \mathrm{~cm}^{-1}\right)$ in the excited state, consistent with an increase of electron density on the bpy-cc-AQ ligand as a whole upon formation of an MLCT excited state. Global analysis of the data results in two components with the lifetimes of $12 \mathrm{ps}$ and a constant in $\mathrm{CH}_{2} \mathrm{Cl}_{2}$, and 8 ps and a constant in $\mathrm{d}_{3}-\mathrm{MeCN}$. The data were analyzed from 300 fs to 4 ns pump-probe delay.

In both solvents, most of the transient features observed are characteristic of a coordinated bipyridine radical-anion, ${ }^{49-50}$ whilst a bleach at $1678-1682 \mathrm{~cm}^{-1}$ and a transient at $1655 \mathrm{~cm}^{-1}$ correspond to AQ-localised vibrations. Transient formation of an additional weak band at $1390 \mathrm{~cm}^{-1}$ (visible in the blue spectrum in Figure 8b, acetonitrile), which is not detected in $\mathrm{CH}_{2} \mathrm{Cl}_{2}$ (Figure 8a, blue spectrum), was also observed. This vibration is characteristic of $\mathrm{AQ}^{-},{ }^{51}$ thus indicating that there is significant charge-separation character in the excited state in MeCN compared to $\mathrm{CH}_{2} \mathrm{Cl}_{2}$. ${ }^{46}$

One may anticipate that in this case the $\mathrm{C} \equiv \mathrm{C}$ stretching vibration would show different spectral signatures in the two different solvents. In both solvents a very weak, broad transient band covering the range of $2000-2200 \mathrm{~cm}^{-1}$ is observed. The low oscillator strength of the $v(\mathrm{C} \equiv \mathrm{C})$ is typical for an organic moiety (Figure S33). The broadness of the band is likely due to the delocalized nature of the MLCT excited state. ${ }^{52}$ Global fit analysis reveals two kinetic components in the high-frequency region in both solvents, with characteristic lifetimes matching those obtained in the low-frequency region of the TRIR spectrum, namely, $13( \pm 3)$ ps in $\mathrm{CH}_{2} \mathrm{Cl}_{2}$ and $7(( \pm 2)$ ps in $\mathrm{MeCN}$, typical of vibrational cooling, along with a long component. In acetonitrile, a clear bleach and a transient corresponding to $v(\mathrm{C} \equiv \mathrm{C})$ superimposed on the broad signal are observed, at $2119 \mathrm{~cm}^{-1}$ and $2114 \mathrm{~cm}^{-1}$, perhaps indicating a more significant participation of the ethynyl linker on the initial charge/energy redistribution.

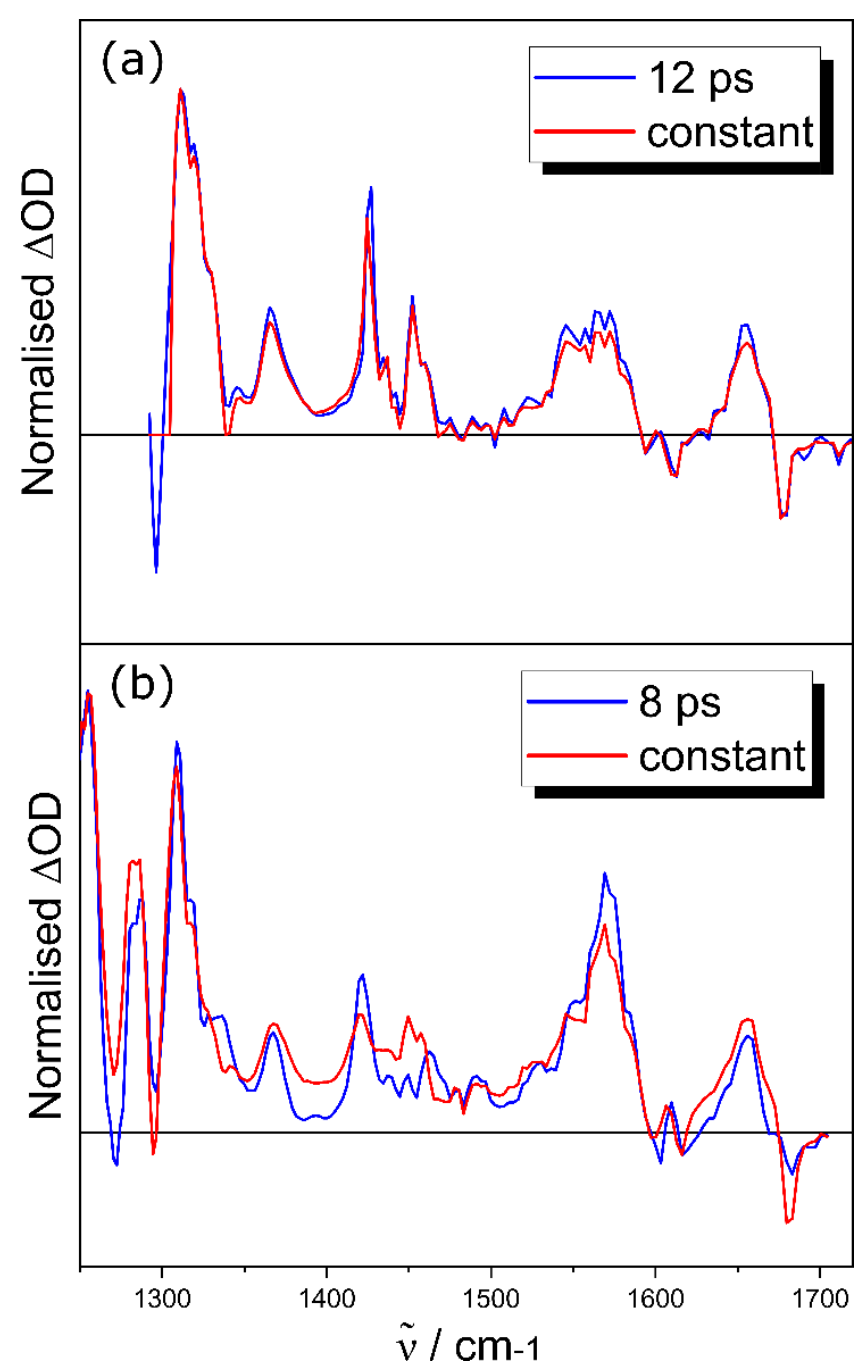

Figure 8. TRIR data obtained in (a) $\mathrm{CH}_{2} \mathrm{Cl}_{2}$ and (b) $\mathrm{d}_{3}-\mathrm{MeCN}$, following excitation with $400 \mathrm{~nm}$, ca. 40 fs laser pulses. Normalized DAS spectra are shown, which correspond to the decay time constants as stated. 'Constant' represents the lifetime longer than the timescale of the experiment, $8 \mathrm{~ns}$.

Overall, the TRIR data directly indicate the presence of an excited state with AQ-localized electron density in $\mathrm{d}_{3}-\mathrm{MeCN}$, which is not observed in $\mathrm{CH}_{2} \mathrm{Cl}_{2}$. The timescale of the decay of this signal is consistent with pseudo-equilibrium between the states being established on the timescale of a few-picoseconds.

\section{CONCLUSIONS}

We have reported a molecular dyad, $\left[\mathrm{Ru}(\mathrm{bpy})_{2}(\mathrm{bpy}-\mathrm{cc}-\mathrm{AQ})\right]^{2+}$, that exhibits solvent-mediated activation/deactivation of PET as a function of both solvent dielectric and hydrogen-bond donor ability, whereby quenching of ${ }^{3} \mathrm{MLCT}$ photoluminescence via intramolecular ET is modulated by several orders of magnitude. 
ns-TA spectra are dominated by MLCT signals and exhibit monoexponential decays with the same lifetimes as the corresponding emission decays in all investigated solvents, whilst ultrafast TA and TRIR spectroscopies provide direct evidence for rapid (on the order of a few picoseconds) pseudo-equilibration between the MLCT and CS states in high polarity solvents, not observed in low polarity solvents.

Within the context of developing viable molecular switches and logic devices, activation/deactivation of ET as a function of solvent is a useful but underexplored proxy to mimic the effects of an external field (such as in a field-effect transistor). Our results demonstrate the high sensitivity of a well-designed molecular system to solvent and inform design principles in the further development of solvent (or external field)-mediated molecular switches.

\section{ASSOCIATED CONTENT}

Supporting Information. Experimental procedures, characterization data, cyclic voltammograms, UV-Vis electronic absorption and emission spectra, UV-Vis spectroelectrochemical data, timecorrelated single photon counting data, physical correlations, ns transient absorption spectra and kinetics, ultrafast transient absorption data, time-resolved infrared data, global fitting analysis, and fit derivations. This material is available free of charge via the Internet at http://pubs.acs.org.

\section{AUTHOR INFORMATION}

\section{Corresponding Author}

Email: cblarsen@stanford.edu, oliver.wenger@unibas.ch, julia.weinstein@sheffield.ac.uk

\section{Author Contributions}

All authors have given approval to the final version of the manuscript.

\section{Funding Sources}

Financial support by the Swiss National Science Foundation through grant numbers 200021_178760 and 206021-157687 is gratefully acknowledged. C. B. L. gratefully acknowledges a Swiss Government Excellence Postdoctoral Scholarship for Foreign Scholars. We thank the Engineering and Physical Sciences Research Council, UK for funding the Lord Porter Laser Laboratory at the University of Sheffield, STFC UK (access to beam time at Rutherford Appleton Laboratory), Dr I Sazanovich (STFC) for collaboration, the Grantham Center for Sustainable Futures (scholarship to M.V.A.), and the University of Sheffield.

\section{REFERENCES}

(1) Andréasson, J.; Pischel, U., Smart Molecules at WorkMimicking Advanced Logic Operations. Chem. Soc. Rev. 2010, 39, 174-188.

(2) Andréasson, J.; Pischel, U., Molecules with a Sense of Logic: A Progress Report. Chem. Soc. Rev. 2015, 44, 1053-1069.

(3) Balzani, V.; Credi, A.; Venturi, M., Molecular Logic Circuits. ChemPhysChem 2003, 4, 49-59.

(4) de Silva, A. P.; McClenaghan, N. D., Molecular-Scale Logic Gates. Chem. Eur. J. 2004, 10, 574-586.

(5) Sense Jan van der, M.; Peter, L., Charge Transport through Molecular Switches. J. Phys.: Condens. Matter 2010, 22, 133001.

(6) de Silva, A. P.; Uchiyama, S., Molecular Logic and Computing. Nat. Nanotechnol. 2007, 2, 399.

(7) Tian, H.; Yang, S., Recent Progresses on Diarylethene Based Photochromic Switches. Chem. Soc. Rev. 2004, 33, 85-97.
(8) Raymo, F. M.; Tomasulo, M., Electron and Energy Transfer Modulation with Photochromic Switches. Chem. Soc. Rev. 2005, 34, 327-336.

(9) Gust, D.; Moore, T. A.; Moore, A. L., Molecular Switches Controlled by Light. Chem. Commun. 2006, 1169-1178.

(10) Gust, D.; Andréasson, J.; Pischel, U.; Moore, T. A.; Moore, A. L., Data and Signal Processing using Photochromic Molecules. Chem. Commun. 2012, 48, 1947-1957.

(11) Copley, G.; Moore, T. A.; Moore, A. L.; Gust, D., Analog Applications of Photochemical Switches. Adv. Mater. 2013, 25, 456461.

(12) Fabbrizzi, L.; Poggi, A., Sensors and Switches from Supramolecular Chemistry. Chem. Soc. Rev. 1995, 24, 197-202.

(13) Daly, B.; Ling, J.; de Silva, A. P., Current Developments in Fluorescent PET (Photoinduced Electron Transfer) Sensors and Switches. Chem. Soc. Rev. 2015, 44, 4203-4211.

(14) de Silva, A. P.; Fox, D. B.; Huxley, A. J. M.; Moody, T. S., Combining Luminescence, Coordination and Electron Transfer for Signalling Purposes. Coord. Chem. Rev. 2000, 205, 41-57.

(15) Valeur, B.; Leray, I., Design Principles of Fluorescent Molecular Sensors for Cation Recognition. Coord. Chem. Rev. 2000, 205, 3-40.

(16) Keefe, M. H.; Benkstein, K. D.; Hupp, J. T., Luminescent Sensor Molecules Based on Coordinated Metals: a Review of Recent Developments. Coord. Chem. Rev. 2000, 205, 201-228.

(17) Gunnlaugsson, T.; Glynn, M.; Tocci, G. M.; Kruger, P. E.; Pfeffer, F. M., Anion Recognition and Sensing in Organic and Aqueous Media using Luminescent and Colorimetric Sensors. Coord. Chem. Rev. 2006, 250, 3094-3117.

(18) Liu, Z.; He, W.; Guo, Z., Metal Coordination in Photoluminescent Sensing. Chem. Soc. Rev. 2013, 42, 1568-1600.

(19) Barbara, P. F.; Meyer, T. J.; Ratner, M. A., Contemporary Issues in Electron Transfer Research. J. Phys. Chem. 1996, 100, 1314813168.

(20) Wasielewski, M. R., Photoinduced Electron Transfer in Supramolecular Systems for Artificial Photosynthesis. Chem. Rev. 1992, 92, 435-461.

(21) Friedman, A. E.; Chambron, J. C.; Sauvage, J. P.; Turro, N. J.; Barton, J. K., A Molecular Light Switch for DNA: $\mathrm{Ru}(\mathrm{bpy})_{2}(\mathrm{dppz})^{2+}$. J. Am. Chem. Soc. 1990, 112, 4960-4962.

(22) Fees, J.; Kaim, W.; Moscherosch, M.; Matheis, W.; Klima, J.; Krejcik, M.; Zalis, S., Electronic Structure of the "Molecular Light Switch" Bis(bipyridine)dipyrido[3, 2-a: 2', 3'c]phenazineruthenium(2+). Cyclic Voltammetric, UV/Visible and EPR/ENDOR Study of Multiply Reduced Complexes and Ligands. Inorg. Chem. 1993, 32, 166-174.

(23) Brennaman, M. K.; Alstrum-Acevedo, J. H.; Fleming, C. N.; Jang, P.; Meyer, T. J.; Papanikolas, J. M., Turning the $\left[\mathrm{Ru}(\mathrm{bpy})_{2} \mathrm{dppz}\right]^{2+}$ Light-Switch On and Off with Temperature. J. Am. Chem. Soc. 2002, 124, 15094-15098.

(24) Brennaman, M. K.; Meyer, T. J.; Papanikolas, J. M., $\left[\mathrm{Ru}(\mathrm{bpy})_{2} \mathrm{dppz}\right]^{2+}$ Light-Switch Mechanism in Protic Solvents as Studied through Temperature-Dependent Lifetime Measurements. J. Phys. Chem. A 2004, 108, 9938-9944.

(25) Hankache, J.; Wenger, O. S., Photoinduced Electron Transfer in Covalent Ruthenium-Anthraquinone Dyads: Relative Importance of Driving-Force, Solvent Polarity, and Donor-Bridge Energy Gap. Phys. Chem. Chem. Phys. 2012, 14, 2685-2692.

(26) Greetham, G. M.; Burgos, P.; Cao, Q.; Clark, I. P.; Codd, P. S.; Farrow, R. C.; George, M. W.; Kogimtzis, M.; Matousek, P.; Parker, A. W.; Pollard, M. R.; Robinson, D. A.; Xin, Z.-J.; Towrie, M., ULTRA: A Unique Instrument for Time-Resolved Spectroscopy. Appl. Spectrosc. 2010, 64, 1311-1319.

(27) Kuss-Petermann, M.; Wenger, O. S., Electron Transfer Rate Maxima at Large Donor-Acceptor Distances. J. Am. Chem. Soc. 2016, $138,1349-1358$.

(28) Larsen, C. B.; Wenger, O. S., Circular Photoinduced Electron Transfer in a Donor-Acceptor-Acceptor Triad. Angew. Chem. Int. Ed. 2018, 57, 841-845.

(29) Han, W.-S.; Veldkamp, B. S.; Dyar, S. M.; Eaton, S. W.; Wasielewski, M. R., Photoinitiated Long-Lived Charge Separation 
with Near-Unity Quantum Yield in Donor-Acceptor 1 -Acceptor 2 Systems for Artificial Photosynthesis. Tetrahedron 2017, 73, 49254935.

(30) Wolf, M.; Villegas, C.; Trukhina, O.; Delgado, J. L.; Torres, T.; Martín, N.; Clark, T.; Guldi, D. M., Mediating Reductive Charge Shift Reactions in Electron Transport Chains. J. Am. Chem. Soc. 2017, 139, 17474-17483.

(31) Dodsworth, E. S.; Lever, A. B. P., Relationships between Electronic Spectroscopy and Electrochemistry. A Probe of Reorganisation Energies. Chem. Phys. Lett. 1985, 119, 61-66.

(32) Dodsworth, E. S.; Lever, A. B. P., Correlations between Electrochemical Potentials and Optical Charge Transfer Energies in Ruthenium Bipyridine Derivatives. Chem. Phys. Lett. 1986, 124, 152158.

(33) Rehm, D.; Weller, A., Kinetics of Fluorescence Quenching by Electron and H-Atom Transfer. Isr. J. Chem. 1970, 8, 259-271.

(34) Marcus, R. A.; Sutin, N., Electron Transfers in Chemistry and Biology. Biochim. Biophys. Acta, Bioenerg. 1985, 811, 265-322.

(35) Lide, D. R., CRC Handbook of Chemistry and Physics, Internet Version. CRC Press: 2005.

(36) Durham, B.; Caspar, J. V.; Nagle, J. K.; Meyer, T. J., Photochemistry of Tris(2, 2'-bipyridine)ruthenium(2+) Ion. J. Am. Chem. Soc. 1982, 104, 4803-4810.

(37) Caspar, J. V.; Meyer, T. J., Photochemistry of Tris(2, 2'bipyridine)ruthenium(2+) Ion $\left(\mathrm{Ru}(\mathrm{bpy})_{3}{ }^{2+}\right)$. Solvent Effects. J. Am. Chem. Soc. 1983, 105, 5583-5590.

(38) Garakyaraghi, S.; McCusker, C. E.; Khan, S.; Koutnik, P.; Bui, A. T.; Castellano, F. N., Enhancing the Visible-Light Absorption and Excited-State Properties of $\mathrm{Cu}(\mathrm{I})$ MLCT Excited States. Inorg. Chem. 2018, 57, 2296-2307.

(39) Hankache, J.; Niemi, M.; Lemmetyinen, H.; Wenger, O. S., Hydrogen-Bonding Effects on the Formation and Lifetimes of ChargeSeparated States in Molecular Triads. J. Phys. Chem. A 2012, 116, 8159-8168.

(40) Gutmann, V., Solvent Effects on the Reactivities of Organometallic Compounds. Coord. Chem. Rev. 1976, 18, 225-255.

(41) Gurzadyan, G. G.; Steenken, S., Solvent-Dependent C-OH Homolysis and Heterolysis in Electronically Excited 9-Fluorenol: The Life and Solvation Time of the 9-Fluorenyl Cation in Water. Chem. Eur. J. 2001, 7, 1808-1815.

(42) Reichardt, C., Empirical Parameters of the Polarity of Solvents. Angew. Chem. Int. Ed. 1965, 4, 29-40.

(43) Reichardt, C., Solvatochromic Dyes as Solvent Polarity Indicators. Chem. Rev. 1994, 94, 2319-2358.

(44) Hankache, J.; Wenger, O. S., Large Increase of the Lifetime of a Charge-Separated State in a Molecular Triad Induced by Hydrogen-Bonding Solvent. Chem. Eur. J. 2012, 18, 6443-6447.

(45) Borgström, M.; Johansson, O.; Lomoth, R.; Baudin, H. B.; Wallin, S.; Sun, L.; Åkermark, B.; Hammarström, L., Electron DonorAcceptor Dyads and Triads Based on Tris(bipyridine)ruthenium(II) and Benzoquinone: Synthesis, Characterization, and Photoinduced Electron Transfer Reactions. Inorg. Chem. 2003, 42, 5173-5184.

(46) Büschel, M.; Stadler, C.; Lambert, C.; Beck, M.; Daub, J., Heterocyclic Quinones as Core Units for Redox Switches: UVvis/NIR, FTIR Spectroelectrochemistry and DFT Salculations on the Vibrational and Electronic Structure of the Radical Anions. $J$. Electroanal. Chem. 2000, 484, 24-32.

(47) Fedoseeva, M.; Delor, M.; Parker, S. C.; Sazanovich, I. V.; Towrie, M.; Parker, A. W.; Weinstein, J. A., Vibrational energy transfer dynamics in ruthenium polypyridine transition metal complexes. Phys. Chem. Chem. Phys. 2015, 17, 1688-1696.

(48) Sazanovich, I. V.; Best, J.; Scattergood, P. A.; Towrie, M.; Tikhomirov, S. A.; Bouganov, O. V.; Meijer, A. J. H. M.; Weinstein, J. A., Ultrafast photoinduced charge transport in Pt(ii) donor-acceptor assembly bearing naphthalimide electron acceptor and phenothiazine electron donor. Phys. Chem. Chem. Phys. 2014, 16, 25775-25788.

(49) Sun, Q.; Dereka, B.; Vauthey, E.; Lawson Daku, L. M.; Hauser, A., Ultrafast transient IR spectroscopy and DFT calculations of ruthenium(ii) polypyridyl complexes. Chem. Sci. 2017, 8, 223-230.
(50) Omberg, K. M.; Schoonover, J. R.; Treadway, J. A.; Leasure, R. M.; Dyer, R. B.; Meyer, T. J., Mid-Infrared Spectrum of $\left[\mathrm{Ru}(\mathrm{bpy})_{3}\right]^{2+*}$. J. Am. Chem. Soc. 1997, 119, 7013-7018.

(51) Orazietti, M.; Kuss-Petermann, M.; Hamm, P.; Wenger, O. S., Light-Driven Electron Accumulation in a Molecular Pentad. Angew. Chem. Int. Ed. 2016, 55, 9407-9410.

(52) Adams, C. J.; Fey, N.; Harrison, Z. A.; Sazanovich, I. V.; Towrie, M.; Weinstein, J. A., Photophysical Properties of Platinum(II)-Acetylide Complexes: the Effect of a Strongly ElectronAccepting Diimine Ligand on Excited-State Structure. Inorg. Chem. 2008, 47, 8242-8257. 
A molecular dyad comprising a $\left[\mathrm{Ru}(\mathrm{bpy})_{3}\right]^{2+}$ photosensitizer and an anthraquinone acceptor exhibits bright ${ }^{3} \mathrm{MLCT}$ photoluminescence in low polarity solvents, which is quenched by intramolecular electron-transfer in high dielectric and hydrogenbonding solvents. The rate of electron-transfer can be tuned over several orders of magnitude by choice of solvent.

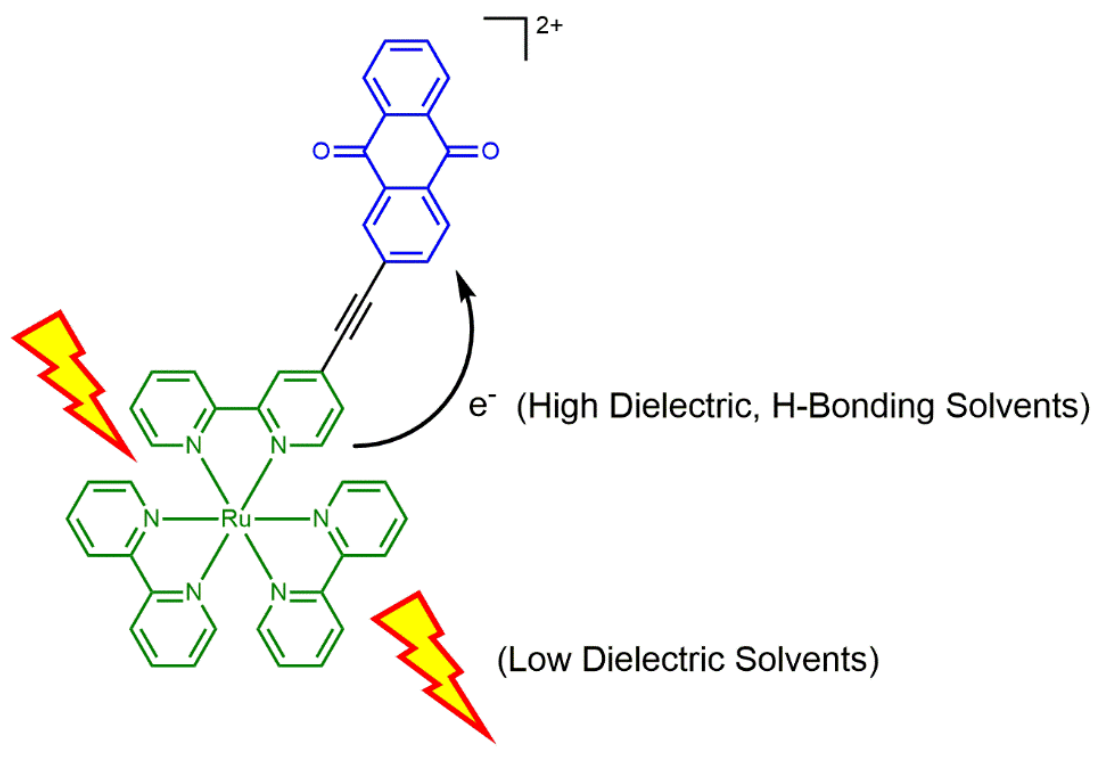

